Please do not remove this page

RMIT

UNIVERSITY

\title{
Methodological entanglements in the field: methods, transitions and transmissions
}

Jungnickel, K.; Hjorth, Larissa

https://researchrepository.rmit.edu.au/esploro/outputs/9921859678801341/filesAndLinks?institution=61RMIT_INST\&index=null

Jungnickel, K., \& Hjorth, L. (2014). Methodological entanglements in the field: methods, transitions and transmissions. Visual Studies, 29(2), 136-145. https://doi.org/10.1080/1472586X.2014.887263

Document Version: Accepted Manuscript

Published Version: https://doi.org/10.1080/1472586X.2014.887263

Repository homepage: https://researchrepository.rmit.edu.au

(C) 2014 International Visual Sociology Association

Downloaded On 2023/04/26 19:52:33 +1000 
Thank you for downloading this document from the RMIT Research Repository.

The RMIT Research Repository is an open access database showcasing the research outputs of RMIT University researchers.

RMIT Research Repository: http://researchbank.rmit.edu.au/

\section{Citation:}

Jungnickel, K and Hjorth, L 2014, 'Methodological entanglements in the field: methods, transitions and transmissions', Visual Studies, vol. 29, no. 2, pp. 136-145

See this record in the RMIT Research Repository at:

https://researchbank.rmit.edu.au/view/rmit:24401

Version: Accepted Manuscript

Copyright Statement: (C) 2014 HERDSA

Link to Published Version:

http://dx.doi.org/10.1080/1472586X.2014.887263 


\section{Methodological Entanglements in the Field: methods, transitions and transmissions}

\section{Kat Jungnickel and Larissa Hjorth}

As this special issue observes, art and ethnography have a long, interconnected and sometimes tacit history. In this paper we explore the interrelationship between methods, transition, and transmission as a way in which to understand both traditions. Both art and ethnography involve processes of transmission and translation from the fieldwork or studio to the reader/gallery. It is this issue of transmission between methods to final outcome - and the types of accountabilities and frameworks - we will focus upon.

While much discussion of art practice within research and university contexts tends to draw from "practice-led" or "practice-based" research (Candy 2006; Sullivan 2010), those practices outside the visual arts that deploying art-related methods and techniques often sit uncomfortably within other disciplines and struggle to be accounted for within official university accountabilities. This situation creates a divide between visual art accountable practices and those that do not fit. It is the latter category we wish to explore. As ethnographic researchers within cultural studies and sociology, the process of making and thinking through art is an integral part of doing research. Through the interdisciplinary process we seek to push boundaries between traditional and non-traditional modes of making, presenting and transmission to audiences.

Although some are reluctant to embrace changes borne of the affordances of digital media, many others favour the transformative potential of new forms of attentiveness to understanding, evoking and provoking the social world (Beer and Burrows 2007; Back 2012, 2012b; Lury and Wakeford 2012). Yet, and possibly because of this, methodological entanglements remain at the forefront of interdisciplinary discussions. Drawing on two projects that blur art and ethnography we set out to explore the possibilities and consequences of an expanded digital and material landscape for thinking about new forms and modes of social description and describers.

In exploring the entanglements between art and ethnography within the context of transmission and storytelling, this paper has two aims. First, it seeks to locate these questions in recent discussions around the role of new qualitative methods for exploring technologically adept, rapidly moving and multi-dimensional social worlds. Beer and Burrows have argued that socio-digital cultures operate 'at a clock speed several orders of magnitude faster than that of academic research' and in many instances are 'moving faster than our ability to analyse it' (2007:1). This points to a potential restructuring of how we engage with social worlds and the means through which we represent our findings. 
As Back writes: 'There is more opportunity to reimagine sociological craft now than at any other point in the disciplines history' (2012: 18). For Lury and Wakeford, the dilemma lies in our need to examine 'inventive methods' whereby methods that cannot be separated from the research problem at hand: 'Inventive methods are ways to introduce answerability into a problem...if methods are to be inventive, they should not leave that problem untouched' (2012: 3). Here, methods arise in the process of doing the research.

Second, we explore how methods themselves do not remain untouched within the practice. As Lury and Wakeford argue, we need to understand how methods are also transformed by the subject and content. These 'methods in the making' are 'methods or means by which the social world is not only investigated, but may also be engaged' (2012: 6). In taking seriously this idea, we explore multiple aspects of touching and being touched by the social world in relation to research methods, paying special attention to how they operate within social contexts, their capacity for 'messiness' (Law 2004), 'thinglyness' (Latour and Yaneva 2008) and the productivity of being an 'irritant' (Michael 2012). Specifically, what we are looking to interrogate is the dynamic interrelation between the method problem, maker, context, respondents etc. Our focus is not just on how research methods emerge from entanglements with the social world but also on how they interweave with the researchers' conventional 'tools of the trade' and re-entangle with the messiness of everyday life.

The structure of the article is as follows. We start by framing the discussion in terms of shifts in methodological discussions that take into consideration the expanding palate of tools for many researchers and artists alike. This is followed by a discussion on transmission in transition and how we might think about vivid descriptions and different ways to know and engage the social. Finally we conclude with a case study of two projects that we conducted that move between art and ethnography in their methods, aesthetics and transmission.

\section{This mess is a method}

This article responds to a growing interest in attending to less fixed and easily representable and more ambiguous, sensory and multiple socio-mobile constructions of everyday life (Law and Urry 2004; Spinney 2011; Pink 2007, 2008; Büscher et al. 2011; Back 2012, 2012b; Jungnickel and Aldred 2013). Büscher et al. call for attempts to resist the 'temptation to hold down and dissect these phenomena to study them' (2011: 1). Similarly, Back asks how we might 'account for the social world without assassinating the life contained within it' (2012: 21). Emphasis here is on the desire to capture 'fleeting, ephemeral and often embodied and sensory aspects of movement' (Spinney 2011: 162). While mobility and transport scholars have been at the forefront of this shift, given the undeniable vivid dynamism of their subject of study, similar moves are evident more broadly in the social sciences and especially in Science and Technology Studies (STS) (Law 2004; Law and Urry 2004; Hine 2012; 
Mess is a theoretical and methodological focus for many scholars in this area of enquiry. Law (2004) defines mess as textures, ideas, objects, artifacts, places, people and emotions that are difficult to deal with within the traditional confines of social science; an indefinable array of complexities that are conventionally ordered and organized in the pursuit of knowledge. He argues that researchers are traditionally trained to extract neat linear arguments from messy and complex worlds but that traditional methodological approaches contradict our own understanding of the world and, in turn, limit the possibilities of other forms of knowing. What this means is that it is becoming increasingly necessary 'to teach ourselves to know some of the realities of the world using methods unusual to or unknown in social science' (Law 2004: 2).

Latour and Yaneva's (2008) research in the area of architectural representational practice argues against the flattening of active processes involved in the production of knowledge. They argue that conventional methods fail to represent the complicated networks of human and non-humans involved in the design process. The constant and messy inter-relations between these actors tend to be flattened, smoothed or otherwise erased form the final form; what looks static is in fact a dynamic and constantly mutable process. To address this reductive process they call for new ways of 'generating earthly accounts of buildings and design processes' and set out to 'tackle the admittedly daunting task of inventing a visual vocabulary that will finally do justice to the thingy nature of buildings' (2008: 88-89). Latour and Yaneva draw on Etienne Jules Marey's famous photographic gun, a technology that arrested the flight of a gull, enabling the viewer to witness every single freeze-frame of a continuous flow of flight in a fixed format. For the first time, the minute movements of a living dynamic thing were transformed into series of fixed images. Latour and Yaneva call for the opposite for buildings; a messy, more energetic representation that would bring to bear ever changing dynamic and multi-dimensional entanglements.

Latour and Yaneva's work draws on Actor Network Theory (ANT) which emerged from early science studies in recognition of the role played by humans as well as nonhumans in complex heterogeneous networks (Law and Hassard 1999; Latour 2005). Rather than privileging the role of technology or that of society in the shaping of a new artefact or system, it contends that both kinds of 'actors' are equally constituted and powerful - they are entangled. In the process of tracing the construction of a building, Latour and Yaneva (2008), examine not only the bricks, glass and steel but also the architects and engineers, their social interactions, sketches and drawings, models, hands, scalpels, stickytape, desks, glue, computers, the general public, weather and many others. Importantly, this approach means that buildings do not exist in isolation but are embedded within complex dynamic heterogeneous actor-networks and that these networks are never fixed in place. They are constantly changing in meaning, touching and being touched by larger social worlds. 
Another relevant example is provided by Michael who explores the anecdote in the realm of social science methodology to see how it might operate less as a subject and more as a 'means of interrogating the research process itself' (2012: 34). He writes about how the 'irritating' qualities of an anecdote are such that they do not fit neatly into nuanced arguments. They do something unexpected, uninvited and in stubbornly refusing to co-operate cannot be completely erased or forgotten.

In any case, insofar as anecdotalization troubles what we are busy doing and is instrumental in inventive problem-making, it suggests that such 'objects' of social science study, as, say, humans and non-humans and their relations are not simply analytic fodder... they end up as something akin to, for want of a better term' 'heterogeneous interlocutors' in the inventive doing of research (Michael 2012: 34).

Dourish and Bell have also explored ubiquitous media as part of larger messier ecologies (2012). This messiness is again not considered negatively but rather in terms of an embedded part of practice that needs to be considered when exploring such media. They develop "a "ubiquitous computing of the present" that takes the messiness of everyday life as a central theme' (2012: 4). They do this by addressing the far ends of mythology (the cultural narratives that shape HCI's research agenda) and messiness (that is, the complex and contested realities of how people actually use and interpret everyday technologies). For Dourish and Bell, messiness is an important part of everyday life and we need methods and theories that openly engage with this mess rather than just trying to tidy them up.

Broadly, what this literature points to is an acceptance of things that do not fit, of mess and surprising things that fall outside expected outcomes and disciplinary edges. Importantly, these things are not viewed as something to be smoothed over, hidden or erased in the final piece of work but are instead viewed as productive and interpretive lenses into social worlds. Taking its cue from this and other literature, the article seeks to embrace the messiness of research by addressing its thingly nature as well as the potential of methods to touch social contexts and operate as irritants in the process of doing research. We especially hold to the idea that 'they are methods and means by which the social world is not only investigated, but may also be engaged' (Lury and Wakeford 2012: 6).

In addition to inventive methods, we are especially interested in inventive modes of transmission of knowledge and approach this in the article from two different perspectives; art and sociology. Transmission in this context is the means by which knowledge is translated and moves. We do not view methods as separate from transmission; they are entangled in the process of doing the research and the following case studies provide a means to materialise this argument. Both combine 
object-oriented practice with ethnography. The entanglements between the two often evolve unevenly and this creates a productive tension. Modes of transmission can be anything from websites, business cards, fridge magnets, games, postcards, videos, exhibitions and catalogues to conference presentations and books. The key to transmission is that it should be procedural and touch the methods in some form or another.

\section{Transmission in transition: Towards vivid description}

The popularity of digital technologies has transformed not only the subject matter for many researchers but greatly expanded the possibilities of communicating and circulating findings to new audiences. Yet debate and discussion about the tactics and techniques of translation has lagged behind their widespread use (Back 2012). Despite pressure to make use of the same tools of which we study, and open up access to data, innovative findings are often transformed back into conventional presentational formats (e.g. conference papers and PowerPoint presentations) with far less attention focused on the possibilities of other forms of knowledge transmission. The result is that an open exploration of new knowledge transmission formats is not as developed as subjects of research and tools by which research is possible. As Back laments:

It remains the case that in social science the inclusion of audio and visual material in the context of ethnographic social research has been little more than 'eye candy' or 'background listening' to the main event on the page (2012: 27).

Nevertheless, we are interested in the inventiveness of methods for artists and ethnographers that operate not just as ways of knowing the social but also for engaging it. This, Lury and Wakeford have argued 'is to be found in the relation between two moments: the addressing of a method - an anecdote, a problem, a category - to a specific problem, and the capacity of what emerges in the use of that method to change the problem' (2012: 7). Laurier et al.'s (2008) study of amateur and professional video editors is one such study that links the role of the researcher's experience in developing new skills and techniques not only in the course of participating in the field for the understanding of a practice but in relation to the broader production of sociological knowledge.

O'Connor's (2005) study of craft cultures in a community glass blowing studio offers a comparative ethnographic approach. She writes about slowly learning to 'twirl' and 'gather' hot molten glass, which 'marked progress for the novice, who, accustomed to serving the instrument, finds the instrument through techniques actually becoming a part of her' (2005: 188). These new skills offered ways to re-consider the theoretical nature of her research into craft. Both researchers adopt a close engagement with their field sites for understanding the nuances and textures of a particular culture and for putting into practice new representational tools for imparting sociological knowledge. 
Yet, while the opportunity to explore messy objects and practices and ways of representing them presents an exciting time in art and the social sciences, in practice it is not so easy and there remain few practical examples. This is especially critical in the context of recognizing the value of such entanglements in comparison to more conventional outputs. For many academics, knowledge transmission is linked to accountability. Universities require particular outcomes in order to comply with established frameworks. For many, the treadmill to produce more traditional outputs has left less space for reflecting and challenging conventions around methods and transmissions. It is not surprising therefore that these processes remain largely unchallenged.

It is still the case that most social scientists view the research encounter as an interface between an observer and the observed, producing either quantitative or qualitative data. Equally, the dissemination of research findings are confined to conventional paper forms of publishing, and research excellence is measured and audited in such forms, be it in monographs or academic journals (Back 2012: 27).

This does not mean that mess or entanglements are absent from conventional research. Rather, that these more untidy aspects of research are hidden or erased as part of an accepted yet largely unspoken part of conventional professional performativity. Often the failures in fieldwork, which are key to making new discoveries, are camouflaged in the process of constructing narratives. Journal articles are structured with clear linear arguments and PowerPoint presentations render the messiness and confusion into a series of easily understood points.

Wakeford (2006) has teased apart the processes by which knowledge is rendered both visible and invisible in her study of PowerPoint, the ubiquitous frame for sociological knowledge. PowerPoint implicitly produces a particular rhythm within the conference venue as concurrent presenters talk through slides, answer questions, load slides, talk through slides, answer questions, load slides etc. The resulting rhythm is one that attempts to streamline ideas and arguments; minimising delays and maintaining viewers attention. Distractions are framed out. Embedded in this notion is that the transmission of knowledge requires neat and narrow linear logics.

Despite the area of mobile media being messy and evolving, conventional modes of transmission - often enforced as part of university workplans - mean that the realities of mess need to be curtailed in order to produce conventional and often out-of-date modes of transmission. For example, Twitter is an important part of the academic landscape for both official and unofficial modes of knowledge exchange (and for some performing social capital). Increasingly conference rooms are full of people tweeting. Each translating the lecture into compressed moments easily a- 
contextualised. And yet, has the lecture structure changed in order to account for these new modes of alternative transmissions that live on beyond the lecture space?

So how do we think through creative ways in which methods, content and transmission might be contextualized differently? What we suggest is to think about how different contexts for reception and discussion can be gleaned from disciplinary and interdisciplinary streams. This is not a mere swapping of art modes with academic ones. Rather we propose to think through how the entanglements between methods and transmission can become stuck and unstuck and why this happens.

In the spirit of mess and entanglement, we draw on two projects introduced earlier to reflect upon collaborative, interdisciplinary practice and the insights gleaned from over a decade of our own work; Keitai mizu (Hjorth) and Enquiry Machines (Jungnickel). We discuss collaborative writing as itself a method of entanglement and the disciplinary backgrounds that frame our individual research approach. We reflect upon the challenges of our own messy experiences in and out of the field and how this has informed our relationship to interdisciplinary methods and tested the limits of conventional methods and modes of knowledge transmission.

\section{Examples of Entanglements: Interdisciplinary projects}

In this section we discuss two projects that sought to bring together art and ethnography in different ways. The first project was a mobile game called keitai mizu (mobile water). Keitai mizu was part of an Australian Research Council linkage Spatial Dialogues that explored the intersections of public art, screen media and climate change in Melbourne, Shanghai and Tokyo. Keitai mizu was formed as part of the collaboration between Spatial Dialogues and Japan's the Boat People Association that took place in Tokyo June 2013 under the title of SHIBUYA: UNDERGROUND STREAMS.

Through a series of video, sound, game and sculptural narratives SHIBUYA: UNDERGROUND STREAMS sought to make the general public in Tokyo consider the underground streams making up much of Tokyo. In particular, the project focused upon one of the busiest places in the world, Shibuya. By placing a shipping container in a park over the month of June, the project sought to explore the idea of cartographies - water, emotional, social, playful, psychological, historical and geographic. Given that Tokyo is made up of numerous little rivers underneath all the trains and roads we wanted to make audiences aware that they are literally perpetually walking on water.

\section{Fig. 1: SHIBUYA: UNDERGROUND STREAMS}

The mobile game, keitai mizu, devised by Hjorth, invited Australian and Japanese artists to respond to an overlay between cartography and water by making water 
creatures. The artists made local and foreign, real and imaginary, representational and abstract creatures that were then placed (and hidden) around the Shibuya Park, Tokyo. Players were invited to camera phone photograph and send as many local water creatures as possible in 15 minutes to the project Twitter account (Fig. 2). The game deployed both old (geocaching) and new (Twitter and Instagram) media to turn players into ethnographers.

The game space was blurred across online and offline spaces with Instagram and Twitter enabling co-present friends to share the experiences and images. Through the process of game play, participants became more mindful of the local water species as well as reflective upon the fact that the city is made up of numerous little rivers underneath all the trains and roads. We wanted to make audiences aware that they are literally perpetually walking on water (Fig. 1).

Fig. 2: Keitai mizu (mobile water) game

Keitai mizu attempted challenge boundaries between official and unofficial game spaces by blurring them with different modes of play (Fig. 3). In particular, camera phone practices partake in new haptic visualities that bring emotional and social dimensions of place and play to the official game play space and drive the motivation for use. By deploying camera phone practices as part of the mobile game, players can develop the melodramatic elements - the affective and emotional dimensions - to engage friends into the play of being mobile.

Part of the enjoyment of the project was not only the entanglements between the methods and its transmission but also how the project lived on in different ways that saw the participants taking the key role. For example, when one student group came through to play, one of the other students took it on herself to document the their experiences and responses and turn it into a short film which she then uploaded onto vimeo. This video was one of the few artifacts of transmission left after the ephemeral work had ceased. Moreover, traces of the play could be found in participants' twitter accounts, creating new nodes for co-present entanglement.

\section{Fig. 3: Keitai mizu players}

Enquiry Machines are a series of hand-made machines, built from cheaply available, abandoned or recycled materials, and designed to invite critical engagement with materials, methods and making practices. There are several in the series and all are collaborations with interdisciplinary practitioners. Jungnickel developed Enquiry Machine \#1 (EM\#1) with Julien McHardy as a means of exploring the labour of sociological knowledge; the work to make arguments and assemblies of material, 
physical and social artifacts and practices. It focuses on the interview; a classic research method for eliciting data. Made of a constellation of bicycle parts, plastic, duct tape, weld and cable ties, this machine requires two operators to co-pedal, collaboratively setting in motion a series of chains, chain rings and cogs to power a dynamo light. In the process, they interview each other about interviewing as a method, bringing to light the sensual, social, emotional, physical, environmental and technological skills required to elicit and make sense of knowledge.

$E M \# 1$ is premised on the idea that although conventional qualitative methods like interviews open up enquiry spaces, little by little, the character and conditions of these interactions are invariably tidied up via the act of translating them into text. Textual interviews can be infinitely edited, manipulated and circulated as objects of knowledge; they are easily transportable and reproducible. Enquiry Machines remind viewers (and operators) that knowledge-making is messy. Although the value of knowledge in alternate forms (beyond talk and text) is gaining purchase in the social sciences, the reality is that messier entanglements are often hidden away from public view, presented in finely crafted textual or visual arguments.

$E M \# 1$ is a direct response to this absence. This instrument of inquiry is so irritatingly awkward that it cannot be flattened. It resists being smoothed over and tidied up. And it fails, often. In the process, it relishes the mess of making, rendering visible the labour of knowledge and the machinations of human and non-human entanglements; it opens up new terrain for interrogating what is revealed and concealed in the production of knowledge. The wearing of blue boiler suits further operates to iterate the labour involved as the operators explore the conversation of mechanics and the mechanics of conversation (Fig. 4).

This machine has been performed as a 'paper' at a European Association of the Study of Science and Technology (EASST) conference in Italy, in public in a Hackney Street, at a Design Salon in a London pub, and more recently the process of making machines has been incorporated into workshop and class based contexts (Jungnickel 2013) (Fig. 5). The project brings to light how knowledge is made from complex collaborative human and non-human encounters are not easy. We work to make knowledge; be that to conduct an interview, make an object, create meaning etc. It requires constant adjustments, tacit knowledge, and sensitivity to timing, balance, tone and environment and many more factors. It demands sensual, physical and material skills. It can be easily interrupted and things do not always go to plan. We also welcome engagement with viewers of the performance - to ask questions viewers climb onto the machine and pedal.

The point of Enquiry Machine \#1 is less about materialising answers or prototyping ideas and more about rendering visible other ways of seeing problems, formulating new critical approaches and literally seeing and touching methods in new ways. It is 
an interdisciplinary entanglement, a material method, mode of transmission and performance.

Fig. 4: Enquiry Machine \#1 in a Hackney Street, London.

Fig. 5. Jungnickel and McHardy operating Enquiry Machine \#1 at EASST, Italy.

At their core, Enquiry Machines are deliberately designed to operate as irritants that push against conventional means of exploring and communicating ideas in the social sciences. They both touch and are touched by methods, makers and materials, so much that they cannot be ignored or cleaned up. To reveal the messy and awkward mechanics of enquiry is itself an outcome that an enquiry machine produces.

\section{Making knowledge is messy: Conclusions on collaborative and interdisciplinary practices}

We need to move on from the arrogant convention in sociology to assimilate other practices on its own terms and within its own image (i.e. a 'sociology of art' or a 'sociology of computing') or a more collaborative practice that is mutually transformative (i.e. sociology with art or sociology with computing). As a consequence I am not suggesting that the boundary between sociology or ethnography can be collapsed with art but I am implying that research practice can be more artful (Back 2012: 33).

Collaboration, like interdisciplinary practice, is highly contextual. It perpetually requires translation as it moves through different transitions and modes. Rather than collapsing art into ethnography, we have outlined some of the ways in which research practice can become more 'artful' by engaging with the methods and their 'annoyingly human' (Back 2004: 138) characteristics as something important in shaping the content and modes of transmission. In this paper we have explored projects that sit within and outside of our disciplines, creating a tension about the importing of methods and their affect upon disciplines and transmission.

This paper began with a friendship made strong through a corresponding desire to play with boundaries between art and ethnography. Over a decade we often said, "We should write together!" We often talked and played in unofficial spaces, mindful of the need to render these unofficial practices into official ones. But herein lay the 
problem - most conferences expected ideas and methods to be simplified into PowerPoints. In industry contexts while the transmission of ideas may have been more flexible, there was still certain accountabilities that needed to be justified. Nothing like the power of PowerPoint or a data visualisation to appease the corporate funders.

Like many, our work has entangled, not directly, but as a result of co-present papers, attendance at conferences, in similar published formats and both are regularly involved in industry research contexts. We have often wondered how we could collaborate around these distinct entanglements, and in particular how we might articulate our engagements in and outside the academy. This paper is the first collaboration as we ponder ways in which to re-configure ideas of ethnographic materials, place, performance and participants.

A central theme in our work is interdisciplinary entanglements. We both operate within and on the edges of their disciplinary boundaries; Hjorth is an artist and digital ethnographer; Jungnickel is a sociologist and maker. For over a decade Hjorth has worked with the socio-cultural and gendered dimensions of mobile media across material and immaterial formations and grappled with the two fields and their potential misunderstandings in transmission. This as had two outcomes. She has removed some of the messiness of fieldwork and play, believing that making art investigated the aesthetic dimensions of mobile media and ethnography explored the ethnical dimensions of participation and reflexivity.

However, within the systems of university accountability, Hjorth has sometimes found it hard to justify the art/ethnography experiments as conventional research. This accountability issue is very important as it inevitably structures the feeling rules and motivations for work practice. More recently it became apparent to her that she had the two explorations mixed up. It was the art making that pushed the ethics of mobile media and the ethnography that considered the aesthetics. This led her to decide to use art and game practice as both a method and a mode of transmission in a recent academic project as part of an Australian Research Council linkage.

Jungnickel is a sociologist at Goldsmiths working on topics related to urban digital technology practices (broadband and wireless fidelity) and mobility cultures (bicycles and buses). Much of her work addresses mundane everyday materials and practices; the use of found, purchased and resourcefully adapted materials and improvised methods to re-imagine information communication technologies. Because making and DiY (Do-it-Yourself) culture is at the heart of much of her work, she reflexively approaches the production of knowledge by making things to make sense of things. Her hands-on practice results in a range of materials and objects; from machines, websites, blogs, films, printed materials, photographs, exhibitions, garments and 
installations. The messiness of this approach brings to light a range of challenges in the context of what is considered a sociological output and process.

This article has been about a modality of articulation; an indexicality of methods and knowledge transmissions. It started with a series of questions that we have sought to explore about the nature of descriptions and describers. While we have raised more questions than answers, what we have sought to do is bring to life is the possibility of new forms of storytelling made possible through the re-imagining of methods, makers and modes of knowledge transmission. The work we have discussed here is an attempt to remain 'annoyingly human' (Back 2004: 138) by exposing open ideas and seeking responses and feedback in a number of ways - to touch and be touched in different ways.

As practices and industries begin to emerge from online and mobile media, there is a need to reassess the material and immaterial, the mobile and immobile in new ways. To understand this phenomenon, we need ethnographic methods that see mobile media as not just a media practice and cultural artifact but also an essential part of the researcher's toolkit that moves in and out of messy mobile spaces. We need to understand and conceptualise the ethnographer's role as exploring co-presence rather than co-location (Beaulieu 2010). We need to understand how haptic interfaces and 'applification' ecologies are relating to the thinglyness of everyday life. We need to understand that co-presence practices inform the ways in which play is localised, contextualised, gendered and generational. We need more spaces for playful inquiry that push boundaries of disciplines and transmission modes.

\section{References}

Back, L. (2012) 'Live sociology: social research and its futures', in L. Back and N. Puwar (eds) Live Methods. Oxford: Blackwell Publishing, pp. 18-39

Back, L. (2012b) 'Tape recorder', in C. Lury and N. Wakeford (eds) Inventive Methods: The happening of the social, London: Routledge, pp. 245-260.

Back, L. (2004) 'Listening With Our Eyes: Portraiture as Urban Encounter', in C. Knowles and P. Sweetman (eds) Picturing the Social Landscape: Visual Methods and the Sociological Imagination, London: Routledge, pp.132-146.

Beaulieu, A. (2010) 'From co-location to co-presence: Shifts in the use of ethnography for the study of knowledge', Social Studies of Science, 40(3): 453-470.

Beer, D. and Burrows, R. (2007) 'Sociology and, of and in Web 2.0: Some initial considerations', Sociological Research Online, 12(5): 17.

Bishop, C. (2006) 'The Social Turn: Collaboration and Its Discontents,' Artforum, February: 179-185.

Büscher, M., Urry, J. and K. Witchger (eds) (2011) Mobile Methods, UK, USA, Canada: Routledge. 
Candy, L. (2006) 'Practice Based Research: A Guide', Creativity \& Cognition Studios (CCS) Available at http://www.mangold-

international.com/fileadmin/Media/References/Publications/Downloads/Practice_Ba sed_Research_A_Guide.pdf

Dourish, P. and G. Bell (2011) Divining a digital future: mess and mythology in ubiquitous computing. Cambridge, Mass: MIT Press.

Foster, H. (1996) 'The Artist as Ethnographer', in The Return of the Real. Cambridge, Mass: MIT Press, pp. 171-204.

Hine C. (2012) The Internet. Understanding Qualitative Research. Oxford: Oxford University Press.

Jungnickel, K. (2013) Enquiry Machines, Research project website, Available at: http://www.katjungnickel.com/portfolio/enquiry-machines/

Jungnickel, K. and R. Aldred (2013) 'Sensory Strategies: How cyclists mediate their exposure to the urban environment'. Mobilities, Published online June 14

Keitai mizu (2013), Available at: http://spatialdialogues.net/tokyo/keitaimizu/, http://spatialdialogues.net/tokyo/live-in-tokyo/audience-response-to-shibuyaunderground-streams/

Krotoski, A. (2013) 'Last Bus to Serendip', BBC Radio 4, 9 Oct, Available at: http://www.bbc.co.uk/programmes/b039d4b4

Krotoski, A. (2012) The Serendipity Engine, Research project website, Available at: http://www.theserendipityengine.com/

Latour, B. (2005) Reassembling the Social; An Introduction to Actor-Network-

Theory. Oxford: Oxford University Press.

Latour, B and A. Yaneva (2008) 'Give me a Gun and I will Make All Buildings Move: An ANT's View of Architecture', in R. Geiser (ed) Explorations in Architecture: Teaching, Design, Research, Basel: Birkhäuser, 80-89.

Laurier, E., Strebel, I. and B. Brown (2008) 'Video Analysis: Lessons from professional Video Editing Practice', Forum: Qualitative Social Research, 9(3), Art. 37.

Law, J. (2004) After Method: Mess in Social Science Research, London: Routledge.

Law, J. and J. Hassard (1999) Actor Network Theory and After, Oxford: Blackwell Publishers.

Lury, C. and N. Wakeford. (eds) (2012) Inventive Methods: The happening of the social, London: Routledge

Michael, M. (2012) 'Anecdote', in C. Lury and N. Wakeford (eds) (2012) Inventive Methods: The happening of the social, London: Routledge, pp.25-35

Morrison, S. (2010) 'Google CEO Envisions a 'Serendipity Engine', 29 Sept, The Wall Street Journal - Tech. Available at: http://online.wsj.com

O'Connor, E. (2005) 'Embodied Knowledge: The Experience of Meaning and the Struggle Towards Proficiency in Glassblowing', Ethnography, 6 (2): 183-204.

Pink, S. (2008) 'An Urban Tour: The sensory sociality of ethnographic placemaking', Ethnography, 9(2): 175-196.

Pink, S. (2007) 'Walking with Video', Visual Studies, 22(3): 240-252. 
Singleton, V. (1998) 'Stabilizing Instabilities: The Role of the Laboratory in the United Kingdom Cervical Screening Programme', in Berg, M. and A. Mol (eds), Differences in Medicine: Unravelling Practices, Techniques and Bodies, Durham, NC: Duke University Press.

Shibuya: underwater streams (2013) http://spatialdialogues.net/tokyo/shibuya/ Spinney, J. (2011) A Chance to Catch a Breath: Using mobile video ethnography in cycling research. Mobilities, 6(2): 161-182.

Sullivan, G. (2010) Art Practice as Research: Inquiry in Visual Arts, Los Angeles: SAGE Publications.

Wakeford, N. (2006) 'Powerpoint and the crafting of social data', EPIC proceedings 